\title{
In vitro effects of methylsulphonylmethane in MCF7 cells
}

\author{
Iş1l YILDIRIM 1 * (D), Çă̆daş AKTAN 2 (D)
}

1 Vocational High School, Pharmacy Services Program, Biochemistry Area, Beykent University, 34500, İstanbul, Turkey

2 Department of Medical Biology, Faculty of Medicine, Beykent University 34500, İstanbul, Turkey

* Corresponding author e-mail: Dr.IsilYildirim@hotmail.com; isil@beykent.edu.tr (I.Y.); 4441997.

Received: 20 January 2020/ Revised: 06 April 2020/ Accepted: 09 April 2020

\begin{abstract}
Methylsulphonylmethane (MSM) is the best source of organic sulfur with the best bio-utilization in the body. MSM provides Sulphur support to fragile tissues such as hair. It provides elasticity to connective tissue. It is required for collagen production. Despite its many advantages, there are only few published papers about the anticancer research regard to MSM, no known studies on Bioinformatics Analysis and the possible mechanisms such an effect remain unknown. Therefore, we aimed to investigate the anticancer effects of MSM associated with a bioinformatics analysis on the breast cancer cell MCF7 and to give the information about possible molecular mechanisms. A cytotoxicity assay was performed using the MTT method. The cell migration analysis was performed using wound healing analysis. An apoptotic effect was performed by DNA fragmentation analysis. A Bioinformatics analysis was performed using a protein data bank. Study results indicated that this component exhibited an anti-proliferative effect as based on dosage increases and it showed apoptotic effects at high concentrations on MCF7 cells and results were supported by previous studies. Consequently, a detailed study of the molecular mechanisms of this matter would allow for the identification of possible new targets for breast cancer treatments.
\end{abstract}

KEYWORKS: Methylsulphonlymethane; apoptosis; cytotoxicity; cysteine; bioinformatics analysis.

\section{INTRODUCTION}

Methylsulfonylmethane (MSM) is an organosulfur compound having the $\mathrm{C}_{2} \mathrm{H}_{6} \mathrm{O}_{2} \mathrm{~S}$ molecular formula. It is a non-toxic, natural organosulfur compound. All the studies from the early 1980s to the present day have showed that MSM has an important role in the cell processes such as differentiation, proliferation and inflammation, as well as antioxidant identification. MSM can reduce the production of enzymes and cytokines that play a role in Reactive Oxygen Species (ROS) production by inhibiting Nuclear Factor Kappa B (NF-kB) transcriptional activity. Reducing the regulation of COX-2 and iOS reduces Superoxide Radical $\left(\mathrm{O}^{-2}\right)$ and Nitric Oxide (NO) formation [1]. Another study, it was determined that the effects of MSM on acute liver injury in rats were induced by carbon tetrachloride $\left(\mathrm{CCl}_{4}\right)$. The results showed that the Cytochrome P450 2E1 (CYP2E1) content was suppressed, while pro-inflammatory cytokines Tumor Necrosis Factor (TNF- $\alpha$ ) and interleukin6 (IL-6) levels increased [2].

The apoptotic mechanism of MSM has been associated with many diseases. For example, in a study, it was researched that the apoptotic effects of MSM linked with acute liver injury in rats were induced by $\mathrm{CCl}_{4}$ and it was determined that on liver tissue induced apoptosis with an increased in Bax / Bcl2 [2]. Various past studies reported on the effects of MSM on signal pathways and the proliferation and apoptotic mechanisms in different cancer cells. The cytotoxic effects and cell cycle analysis of MSM on human hepatocellular carcinoma (HepG2) human esophageal squamous cell carcinoma (KYSE-30), human gastric cancer (AGS) cell lines were also analyzed and cell cycle analysis results showed a significantly reduction in the cell population of the G1 phase compared with the control group. The decrease in cell population at the G1 phase indicated that the cells started apoptosis [3]. In another study it was reported that the MSM activated Poly ADP-Ribose Polymerase (PARP) division and induced apoptosis in HepG2, Huh7-Moc4 [4].

A report published by the Karabay et al. indicated that Macrophage-like cells treatment with MSM, was induced caspase- 3 activation by cytochrome c release. In addition, the Bax / Bcl-2 ratio significantly decreased and the PARP cleavage notably increased. In addition, the loss of mitochondrial membrane potential was reduced with MSM pre-treatments in the activated macrophages [5]. According to a study published in 2016, it was found that MSM provided a differentiation of mesenchymal stem cell (MSC) to osteoblasts via Janus kinase 2 (Jak2) /Signal Transduction and the Transcription Activator (STAT) 5b signaling pathways [6]. 
In an effort to determine the mechanisms of action of MSM on apoptosis in HCT116 colon cancer cells, it was discovered that a treatment of MSM inhibited cell viability and an induced apoptosis of HCT-116 p53 +/+ and HCT-116 p53 -/- colon cancer cells. Both cell lines showed an increase in PARP cleavage and caspase3 activity. Study results showed that MSM-induced apoptosis associated with p53-independent and C-Jun Nterminal kinases (JNK) phosphorylation increased in both cell lines as dose-dependently [7].

In their study Lim et al. identified in that MSM suppressed the phosphorylation of STAT3, STAT5b, the expression of IGF-1R, HIF-1a, VEGF, BrK, and p-IGF-1R and inhibited the estrogen negative receptor MDAMB-231 and Balb/c in athymic nude mice cells. They confirmed that MSM was effective against breast cancer growth by regulating multiple targets including STAT3/VEGF and STAT5b/IGF-1b, however, it showed no effect on human immortalized breast cell MCF 10A [8].

It was determined that MSM inhibited cell proliferation and induced apoptosis in the metastatic YD-38 cell lines. An MSM upregulated expression of P21Waf1/Cip1 and P27Kip1 and P27Kip1 genes caused a downregulated expression of cyclin D1 (CCND1) and CDK4. In addition, treatments with MSM induced apoptosis and an up-regulation of Bax, inhibited the expression of the Bcl-2 and Bcl-x, and so the MSM-induced apoptosis come true caspase-mediated. [9]. In another previous study, Bax protein levels were determined using a Western blotting analysis in the MCF7 cells with treatment with MSM and Tam combination for 24 hours in a prior study. The results obtained showed that the bands were weak even at high concentrations of apoptosis associated with Bax, however, it appears to be a more potent band with a synergistic effect [10].

Our purpose of this study was to investigate the anticancer effects of MSM associate with bioinformatics analysis on breast cancer cell MCF7 and give to information about possible molecular mechanisms.

\section{RESULTS}

\subsection{Cytotoxic effect result}

MCF7 cells exposed to MSM compound serial dilutions 10; 50; 100; 200; 300; 400 and 500mM concentrations for 24 hours and results are shown in Figure 1.

When the MCF7 cells exposed to MSM compound serial dilutions 10; 50; 100; 200; 300; 400 and 500mM concentrations for $24 \mathrm{~h}$, the cell proliferation decreased in $97.055 \pm 3.926 ; 80.312 \pm 4.432 ; 58.865 \pm 3.186 ; 48.501$ $\pm 5.311 ; 41.418 \pm 5.865 ; 35.701 \pm 2.644 ;$ and $27.366 \pm 3.102 \%$ respectively compared to control group. Cytotoxic effect at the highest concentration was 3.5 times higher than the lowest concentration. The statistical significance values were found for 50, 200, 300 and $400 \mathrm{mM}$ ( $p<0.01)$, but for 100 and $500 \mathrm{mM}$ were $\mathrm{p}<0.001$.

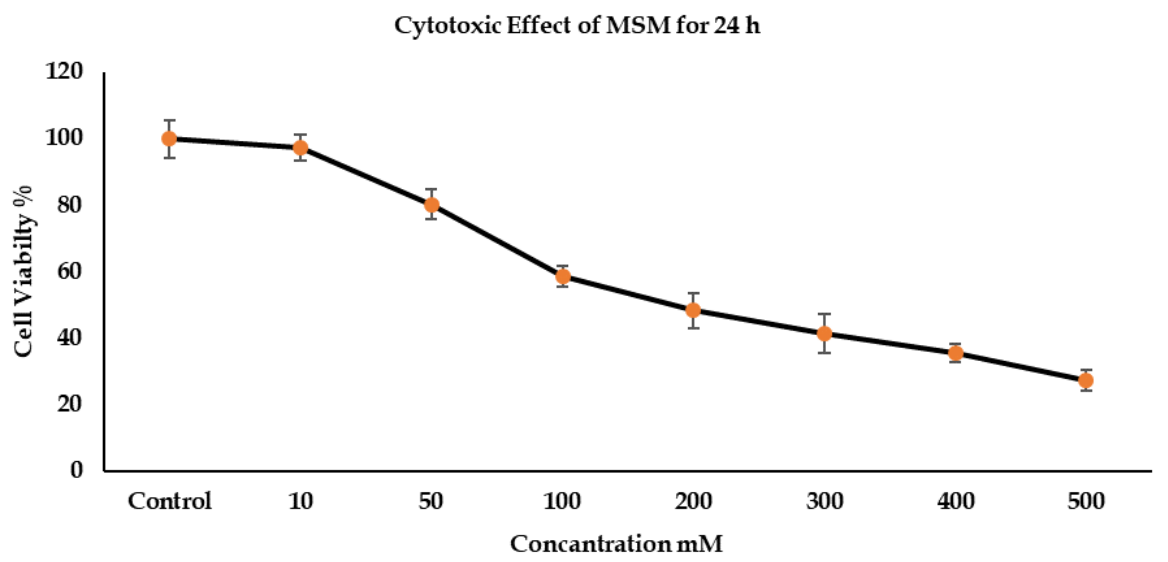

Figure 1. Cytotoxic effect of MSM on MCF7 cells at $24 \mathrm{~h}$ were represented as mean $\pm S D, n=6$.

\subsection{DNA fragmentation analysis results}

DNA fragmentation analysis results of MCF7 cells exposed to MSM compound are shown in Figure 2. The classical method to detect DNA ladders is to examine fragmented genomic DNA on an agarose gel. After a 24-hour incubation, it appears that the apoptosis-inducing fragmentation may have started by DNA fragmentation analysis, the apoptotic effect was determined only at the highest concentration of $500 \mathrm{mM}$. 


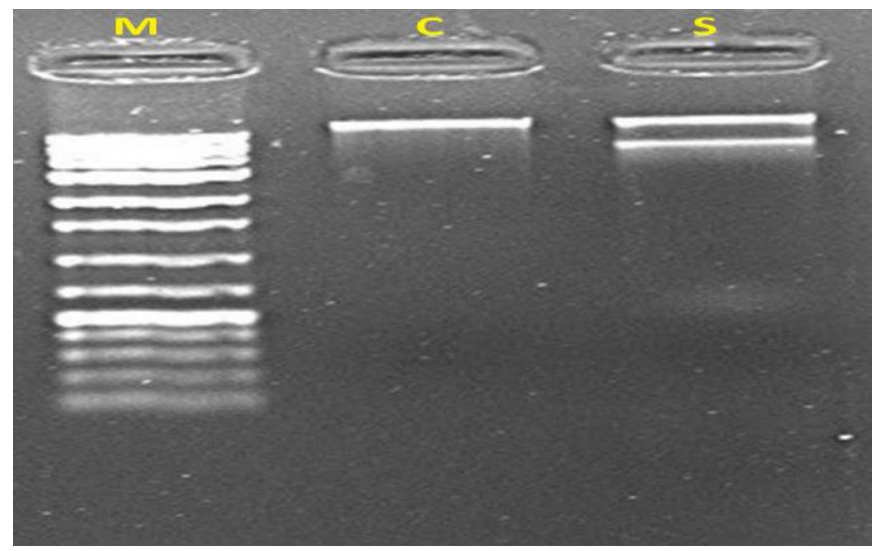

Figure 2. DNA fragmentation analysis results.

M: Marker, C: Control, S: Sample (500 mM concentration).

\subsection{Bioinformatic analysis results}

Bioinformatic analysis results are shown in Figure 3. Bcl-2 and Bcl-xl are well known proteins on apoptotic pathway. So, we done bioinformatics analysis for these genes, firstly. The interactions of Bcl-2 and Bcl-xl proteins involved in the apoptotic pathway were investigated for 4IEH and 5C3G structures, respectively. Potent active regions of proteins were determined by accelrys discovery and virtual screening was performed with Vina using the relevant region Pyrex. As a result, it is seen that MSM has little effect on these proteins Figure 3. It may be thought that it acts indirectly on other proteins and indirectly affects apoptosis, thus supporting other researchers to support this study may contribute to the development of MSM as an anticancer drug and it is thought that there may be great hope in treatments.

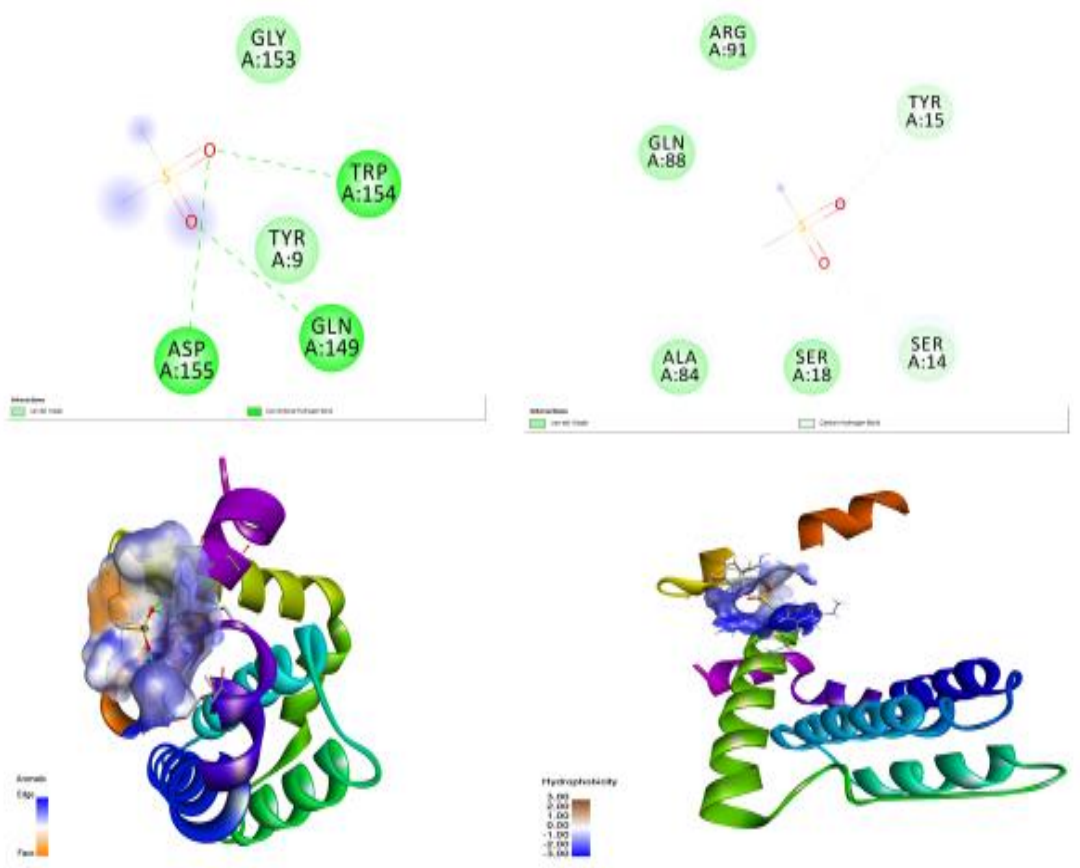

Figure 3. Bioinformatics analysis results.

\subsection{Wound healing results}

The cells treated with MSM are shown in Figure 4 after 24 hours' incubation for wound healing at 0, 12, 24 , and 48 hours. According a qualitative result of the wound healing assay, cell migration was accelerated based on time in MSM-treated MCF7 cells. It seems that the wounds are fully healed 48 hours. The results are shown in Figure 4. 


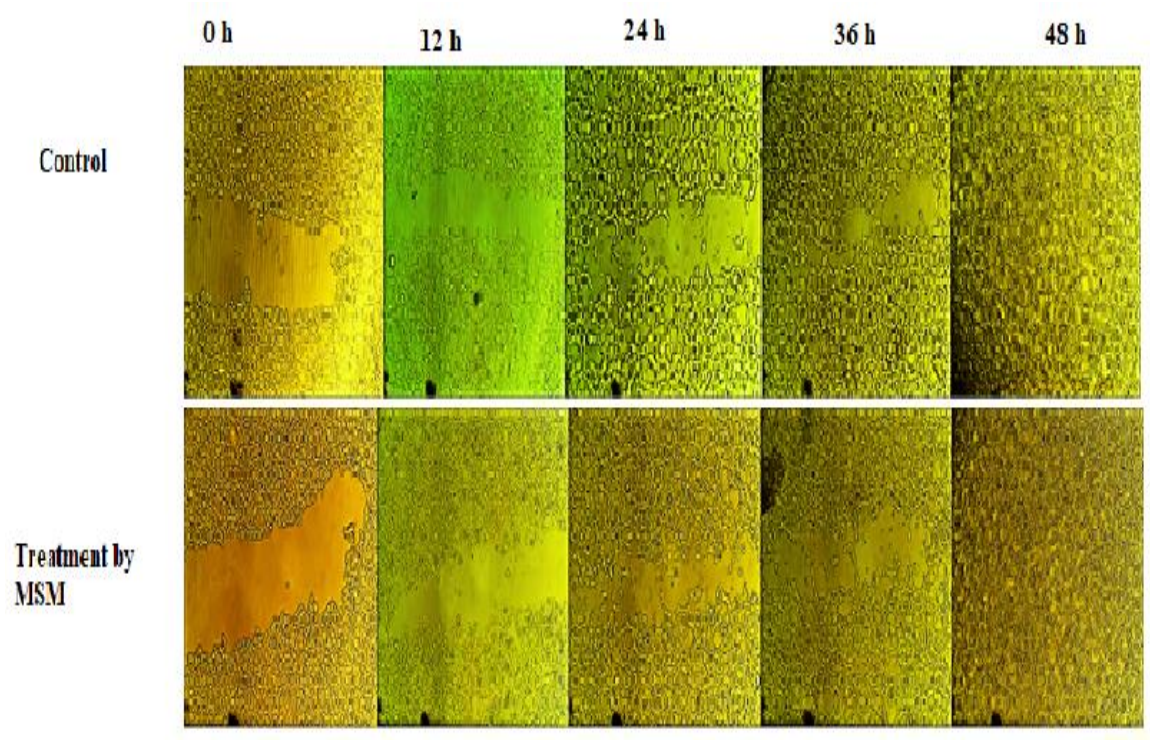

Figure 4. A wound healing assay showing the migration inhibition of MCF7 cells treated with MSM.

\section{DISCUSSION}

Sulfur-containing molecules play significant roles in the anticancer mechanism. Sulfur manifests its influence on platinum anticancer chemotherapy in two aspects: Exogenous effects such as side, toxic effect. There are several endogenous sulfur-containing molecules such as Cysteine, Methionine, Glutathione, and Metallothionein (MT). These amino acids are known as the sulfur-bearing amino acids. The sulfur-bearing amino acid cysteine is absolutely essential to health and it plays important roles in maintaining the integrity of cellular systems by influencing the cellular redox state and the capacity to detoxify toxic compounds, free radicals and reactive oxygen species [11]. MSM provides a benefit for glutathione enzymes in oxidant defense and may be a secondary route to remove sulfur deficiency. The oxidant effect of cysteine residues associated with the formation of disulphide bonds between protein thiol groups which has an important role in sulfur metabolism [12]. This metabolism of thiolation occurs in with several ways such as to regulate several metabolic processes including enzyme activity, transport activity, signal transduction and gene expression targeting redox-sensitive nuclear transcription factors such as AP-1, NF-k $\beta$ and p53 [13]. For example, previously, a study it was reported that the role of sulfur amino acid metabolism in chemotherapy resistance remains to be identified. It was determined that cysteine concentration decreased significantly in the cell culture medium and increased Glutathione (GSH) in the environment in Tamoxifen resistant MCF7 cells. This case demonstrates the utilization of cysteine [14]. Because cysteine is an important amino acid for intracellular GSH synthesis and it is exhibits anti-carcinogenesis and anticancer activity through targeting either their effect on increasing GSH concentration in relevant tissues or it induces of immunity through the GSH pathway [15].

We demonstrated in our study, MSM strongly inhibited MCF7 cell proliferation compared to the control group after 24 hours. When the MCF7 cells are exposed to MSM compounds, they showed a cytotoxic effect due to dose increases (Figure 1). Cell viability was found to be about $97 \%$ in the lowest dose, while the highest concentration was found to be $27 \%$ at $500 \mathrm{mM}$. Moreover, the $\mathrm{IC}_{50}$ values of the MSM were found to be 180 $\mathrm{mM}$ in the MCF7 cells. The $\mathrm{IC}_{50}$ levels of MSM and $15 \mu \mathrm{M}$ of Tamoxifen were found to be $200 \mathrm{mM}$ in a previous study [10].

It has been identified that the MSM showed a cytotoxic effect in MCF7 cancer cells [16, 17]. It was also determined that MSM inhibited the proliferation in SK-BR3 and MCF7 cells [18]. As a result, these studies verified that the cell proliferation results that were found in the previous studies were consistent with our results.

Previously studies reported that MSM could dramatically reduce the viability of human breast cancer cells contact-inhibition signaling in the cell proliferation that occurs during healing [19]. In another study, it was reported that the anticancer effect of MSM was associated with wound healing and contact inhibition. In results, it was found that MSM could inhibit cell migration through the extracellular matrix in various types of breast cancer 66cl-4 cells [20]. Our study determined that MSM accelerated cells migration depending on 
the time during wound healing (Figure 4). Because accelerated or inhibited cell migration during wound healing varies from different cancer cells, more detailed molecular studies are required.

DNA Fragmentation plays an important part in forensics, especially that of DNA profiling. A distinctive biochemical feature of apoptosis is the fragmentation of DNA by a specific nuclease called caspase-activated DNAase (CAD). Activation of CAD by the caspase cascade leads to specific cleavage of DNA at inter nucleosome linker sites, generating fragments of $\sim 200$ base pairs known as DNA ladders. In our study, we performed this DNA fragmentation. According to the DNA Fragmentation analysis results (Figure 2) it was determined that after the treatment with MSM, fragmentation which is a marker of apoptosis appears to have begun.

In previous literature [10] the flow cytometry method was used and apoptosis was observed in MCF7 cells treated with MSM. The apoptotic effect of MSM found 33\% of late apoptotic and $22.18 \%$ of early apoptotic cell deaths and were then compared to the control group. Although the methods were different, MSM was shown to induce apoptosis in MCF7 cells. Although many genes play a role in the mechanism of apoptosis, Bax, Bcl-2 and Bcl-xl are the most well-known. Bax highlights critical amino acid residues (e.g. Cys126, Thr167, Pro168, Pro13 and Ser184). Cys62 within Ha2 close to the BH3 domain and Cys126 between the Ha5 and Ha6 are both exposed and potentially form a disulfide bridge for homo or hetero dimerization [21-23] a promotion of a cytochrome c release [24] and in the results caspase activation and cell death. We have found that the Baxmediated apoptosis was affected by other proteins more than cysteine (Figure 3). By expanding the bioinformatics analysis, the interaction with proteins in the apoptosis pathway as well as the expression of proteins associated with it can be looked at with a functional analysis such as Western blot.

\section{CONCLUSIONS}

Recognizing the biological processes underlying in the disease, and the associated with molecular mechanisms in the various treatments that all play an important role in the development of anti-cancer drugs which can be used to prevent or inhibit the growth of cancerous cells. Although our study is limited, analysis of genes (Bax, Bcl-2 and Bcl-x1) that may be related to qPCR, and the determination of protein expression levels by western blotting, as well as bioinformatics analysis including other apoptotic proteins are among the future planned objectives of the study. However, MSM should be considered to have a possible anticancer agent potential related with glutathione, which is its mechanism of action. So, we will also consider glutathione-mediated apoptosis in our next study. However, the more possible mechanisms of MSM in breast cancer need to discover and further clinical studies are required. Therefore, we anticipate that this article can be the guide for future studies. Furthermore, supporting other researchers and their exploration into this matter may contribute to the development of MSM as an anticancer drug and it is anticipated that there may be great hope in future treatments.

\section{MATERIAL AND METHODS}

Human breast adenocarcinoma MCF7 cell was obtained from ATCC (USA). Dulbecco's Modified Eagle Medium (DMEM; Catalog No: D6429), 3-(4,5-Dimethyl-2-thiazolyl)-2,5-diphenyl-2H-tetrazolium bromide (MTT: Catalog No: Sigma, M2128), Penicillin-Streptomycin (Catalog No: P4333), Trypsin-EDTA solution (Catalog No: T4049), 2-Mercaptoethanol (Catalog No:M7522) were purchased from Sigma-Aldrich (Germany). Fetal Bovine Serum (FBS; GIBCOTM 26140079) and Sodium Dodecyl Sulphate (SDS; L3771) was purchased from Sigma Aldrich. flasks and 96-well plates (Greiner) were used for cell culture and viability assays, respectively. The DNA Ladders (Gene Ruler $1 \mathrm{~kb}$ DNA) were purchased from Thermo Scientific (USA). Tris was purchased from Roche. The MSM was purchased from Boga Medical-mediated international Firm (CAS No: 67-71-0).

A Thermo Scientific $\mathrm{CO}_{2}$ incubator was used and an Emax® Plus ELISA a laminar flow cabinet was used. SOIF Mark, XDY2 Model Inverted Fluorescent Microscope, MSHOT Mark, MD 505 MP resolution model CMOS Camera, Bio-Rad Benchmark Microplate Reader, Stuart mark vortex, Thermo mark Horizontal Electrophoresis, BECKMAN mark micro centrifuges-microfuge Beckman Coulter Allegra X-30 mark refrigerated Centrifuge were also used $75 \mathrm{~mL}$ polystyrene flask were used for cell culture.

\subsection{Cell culture and treatment}

MCF7 cells were grown in DMEM medium containing L-glutamine, 1\% penicillin/streptomycin, $1 \%$ sodium pyruvate, $1 \%$-mercaptoethanol and a $10 \%$ (FBS) at $37^{\circ} \mathrm{C}$ in $5 \% \mathrm{CO}_{2}$ atmosphere. At the beginning of each experiment, the cells were re-suspended in the medium at a density of $1 \times 10^{5} \mathrm{cells} / \mathrm{ml}$. MSM was 
dissolved using at $10 \mathrm{ml}$ distilled water. Cells were treated with MSM at 10, 100, 200, 300, $500 \mathrm{mM}$ concentrations for 24 hours.

\subsection{Assessment of cytotoxic effect}

The measurement of the cytotoxic effect using the MTT assay was performed in 96-well plate using the MCF7 breast cancer cells. After the cells were grown in the DMEM, they were re-suspended in the medium for one more day before the drug treatment. $90 \mu \mathrm{l}$ of cell cultures were dispensed into 96 -well round-bottom plates containing $10 \mu \mathrm{l}$ of MSM compound dilutions. The plates were incubated in a $37^{\circ} \mathrm{C}$ incubator containing $5 \% \mathrm{CO}_{2}$ for 24 hours. After incubation, $10 \mu \mathrm{l}$ freshly prepared MTT solution $(5 \mathrm{mg} / \mathrm{ml})$ in phosphate buffer saline (PBS) was added to each well and the plates were incubated for 4 hours. At the end of the incubation time, the $80 \%$ medium was removed from all wells and the $100 \mu \mathrm{l}$ which was added to a mixture of sodium dodecyl sulfate (SDS, pH 5.5) dissolved in $50 \%$ isopropyl alcohol was added to the wells. After 15 minutes of incubation at $37^{\circ} \mathrm{C}$ in the dark, in order to dissolve the formazan crystals formed by reduction of MTT in living cells. The optical density (OD) of the color was measured using a Bio-Rad Benchmark Microplate Reader. For the controls, only the cells incubated with the medium were used. The cytotoxicity assay was repeated six times for each concentration of the compound. The mean absorbance, percentage cell viability, and $\mathrm{IC}_{50}$ values were calculated using EXCEL software.

\subsection{Apoptotic DNA fragmentation analysis}

The apoptotic effect was determined using DNA fragmentation analysis. MCF7 cells were incubated at the highest effective concentration for 24 hours. As a control, a different flask of MCF7 cells were incubated with the medium only. At the end of the incubation time, the cell solutions were transferred to a centrifuge tube and centrifuged at $13200 \mathrm{rpm}$ speed for 5 seconds at room temperature. Then, the supernatant was discarded. Then $600 \mu$ ice-cold cell lysis buffer $(10 \mathrm{mM}$ Tris- $\mathrm{Cl}(\mathrm{pH}: 8)$, was added to it. Then $3 \mu$ of proteinase $\mathrm{K}$ was added to cell solutions and incubated for $3 \mathrm{~h}$ at $55^{\circ} \mathrm{C}$. followed by $1.5 \mu \mathrm{l}$ of RNAase $(4 \mathrm{mg} / \mathrm{ml})$ and an additional incubation for 15 minutes at $37^{\circ} \mathrm{C}$. Then, the samples were cooled down to room temperature and $200 \mu \mathrm{l}$ of the potassium acetate solution was added and mixed. The samples were centrifuged at $13200 \mathrm{rpm}$ speed for 3 minutes at $4^{\circ} \mathrm{C}$. The supernatant was removed then transferred to a new micro centrifuge tubes followed by the addition of $600 \mu \mathrm{l}$ isopropanol. The solution mixed and centrifuged at room temperature for 1 minute at 13200rpm speed. The supernatant removed and $600 \mu \mathrm{l}$ ethanol $(70 \%)$ was added to the remaining DNA pellet. The tube was centrifuged at room temperature for 1 minute at maximum speed and the supernatant was removed and the DNA pellet was allowed to air dried for 15 minutes. Then, $100 \mu \mathrm{l}$ of TE buffer was added to the pellet. The isolated genomic DNA were run on a $2 \%$ agarose gel electrophoresis for 40 minutes at 100 volts stained in an Ethidium bromide solution $(0.625 \mathrm{mg} / \mathrm{ml})$ for $\mathrm{x}$ minutes and analyzed on a gel imaging system (Vilber Lourmat -02).

\subsection{Wound healing assay}

A wound healing test was performed for an analysis of cell migration of MCF7 cells. Cells were incubated with the substance for 24 hours after reaching approximately $90-100 \%$ confluence. As a control, the cells were incubated with the medium only, after becoming a confluent monolayer, the cell layers were draw with using a sterile pipette. Cells were treated with the substance at the highest concentration $(500 \mathrm{mM})$ of MSM and cell migration at $0,12,24,36,48$ hours was examined.

\subsection{Statistical analysis}

Statistical analysis for cytotoxicity was performed using the by Excel software program and comparison between mean values for cytotoxicity were calculated by Student's t-tests.

\subsection{Bioinformatics analysis}

The protein data bank (https://www.rcsb.org) was used for bioinformatics analysis. The PDB archive contains information about experimentally-determined structures of proteins, nucleic acids, and complex assemblies. As a member of the ${ }_{w w P D B}$, the RCSB, PDB curates and annotates PDB data according to agree upon standards. The RCS and PDB also provides a variety of tools and resources. Users can perform simple and advanced searches based on annotations relating to sequence. Bioinformatics analysis results were shown in Figure 3. 
Acknowledgements: Studies was carried out in the Uskudar University, Department of Molecular Biology and Genetic, Cell Culture Research Laboratory. As a corresponding author, I thanks to Assistant Professor Dr. Çağdaş AKTAN for contributions to Bioinformatics analysis.

Author contributions: Concept I.Y.; Design -I.Y.; Supervision -I.Y.; Resources - I.Y; Materials- Üsküdar University. Data Collection and/or Processing - I.Y., Ç.A.; Analysis and/or Interpretation - I.Y., Ç.A.; Literature Search - I.Y.; Writing - I.Y.; Critical Reviews - I.Y., Ç.A.

Conflict of interest statement: The authors declared no conflict of interest in the manuscript.

\section{REFERENCES}

[1] Kim Y, Kim D, Lim H, Baek D, Shin H, Kim J. The Anti-Inflammatory Effects of Methylsulfonylmethane on Lipopolysaccharide-Induced Inflammatory Responses in Murine Macrophages. Biol Pharm Bull. 2009; 2: 651-656. [CrossRef]

[2] Kamel R, El Morsy EM. Hepatoprotective Effect of Methylsulfonylmethane against Carbon Tetrachloride-Induced Acute Liver Injury in Rats. Arch Pharm Res. 2013; 36(9): 1140-1148. [CrossRef]

[3] Jafari N, Bohlooli S, Mohammedi S, Mazani M. Cytotoxicity of Methylsulfonylmethane on Gastrointestinal (AGS, HepG2, and KEYSE-30) Cancer Cell Lines. J Gastrointest Cancer. 2012; 43: 420-425. [CrossRef]

[4] Kim JH, Shin HJ, Ha HL, Park YH, Kwon TH, Jung MR, Moon HB, Cho ES, Son HY, Yu DY. Methylsulfonylmethane Suppresses Hepatic Tumor Development through Activation of Apoptosis. World J Hepatol. 2014; 6(2): 98-106. [CrossRef]

[5] Karabay AZ, Aktan F, Sunguroğlu A, Büyükbingöl Z. Methylsulfonylmethane Modulates Apoptosis of LPS/IFN- $\Gamma-$ Activated RAW 264.7 Macrophage-Like Cells by Targeting P53, Bax, Bcl-2, Cytochrome C and PARP Proteins. Immunopharmacology Immunotoxicol. 2014; 36(6): 379-89. [CrossRef]

[6] Kim DN, Joung YH, Darvin P, Kang DY, SP N, Byon HJ, Cho KH, Park KD, Lee HK, Yang YM. Methylsulfonylmethane Enhances BMP-2-Induced Osteoblast Differentiation in Mesenchymal Stem Cells. Mol Med Rep. 2016; 14: 460-466. [CrossRef]

[7] Karabay AZ, Koç A, Özkan T, Hekmatshoar Y, Sunguroğlu A, Aktan F, Buyukbingol Z Methylsulfonylmethane Induces P53 Independent Apoptosis in HCT-116 Colon Cancer Cells. Int J Mol Sci. 2016; 17(1123): 1-19. [CrossRef]

[8] Lim EJ, Hong DY, Park JH, Joung YH, Darvin P, Kim SY, Na YM, Hwang TS, Ye SK, Moon ES, Cho BW, Do Park K, Lee HK, Park T, Yang YM. Methylsulfonylmethane Suppresses Breast Cancer Growth by Down-Regulating STAT3 and STAT5b Pathways. PLOS ONE. 2012; 7(4): e33361. [CrossRef]

[9] P NS, Kang DY, Kim BJ, Joung YH, Darvin P, Byun HJ, Kim JG, Park JU, Yang YM. Methylsulfonylmethane Induces G1 Arrest and Mitochondrial Apoptosis in YD-38 Gingival Cancer Cells. Anticancer Res. 2017; 37: $1637-1646$. [CrossRef]

[10] Nipin S, Darvin P, Yoo YB, Joung YH, Kang DY, Kim DN, Hwang TS, Kim SY, Kim WS, Lee HK, Cho BW, Kim HS, Park KD, Park JH, Chang SH, Yang YM. The Combination of Methylsulfonylmethane and Tamoxifen Inhibits the Jak2/STAT5b Pathway and Synergistically Inhibits Tumor Growth and Metastasis in ER-Positive Breast Cancer Xenografts. BMC Cancer. 2015; 5: 474. [CrossRef]

[11] Wang Xi, Guo Z. The Role of Sulfur in Platinum Anticancer Chemotherapy. Anticancer Agents Med Chem 2007; 7: 19-34. [CrossRef]

[12] Hohn A, Jung T, Grune T. Pathophysiological importance of aggregated damaged proteins. Free Radic Biol Med. 2014; 71: 70-89. [CrossRef]

[13] Townsend DM, Tew KD, Tapiero H. The Importance of Glutathione in Human Disease. Biomed Pharmacotherapy. 2003; 57(3): 145-155. [CrossRef]

[14] Ryu CS, Kwak HC, Lee JY, Oh SJ, Phoung NT, Kang KW, Kim SK. Elevation of cysteine consumption in tamoxifenresistant MCF-7 cells. Biochem Pharmacol. 2013; 85(2): 197-206. [CrossRef]

[15] Bounous G. Whey protein concentrate (WPC) and glutathione modulation in cancer treatment. Anticancer Res. 2000; 20(6C): 4785-92.

[16] Sarkhani E, Najafzadeh N, Tata N, Dastan M, Mazani M, Arzanlou M. Molecular mechanisms of Methylsulfonylmethane and allicin in the inhibition of CD44 \pm breast cancer cells growth. J Funct Foods. 2017; 39: 5057. [CrossRef] 
[17] Caron JM, Caron JM. Methyl Sulfone Blocked Multiple Hypoxia- and Non-Hypoxia-Induced Metastatic Targets in Breast Cancer Cells and Melanoma Cells. PLOS ONE. 2015; 10: e0141565. [CrossRef]

[18] Kang DY, Darvin P, Yoo YB, Joung YH, SP N, Byon HJ, Yang YM. Methylsulfonylmethane Inhibits HER2 Expression through STAT5b in Breast Cancer Cells. Int J Oncol. 2016; 48: 836-842. [CrossRef]

[19] Ebisuzaki K. Aspirin and Methylsulfonylmethane (MSM): A Search for Common Mechanisms, With Implications for Cancer Prevention. Anticancer Res. 2003; 23(1A): 453-8.

[20] Caron JM, Monteagudo L, Sanders M, Bannon M, Deckers PJ. Methyl Sulfone Manifests Anticancer Activity in a Metastatic Murine Breast Cancer Cell Line and in Human Breast Cancer Tissue-Part 2: Human Breast Cancer Tissue. Chemotherapy. 2013; 59(1): 24-34. [CrossRef]

[21] D'Alessio M, De Nicola M, Coppola S, Gualandi G, Pugliese L, Cerella C, Cristofanon S, Civitareale P, Ciriolo MR, Bergamaschi A, Magrini A, Ghibelli L. Oxidative Bax dimerization promotes its translocation to mitochondria independently of apoptosis. FASEB J. 2005; 19(11): 1504-1506. [CrossRef]

[22] Gilmore AP, Metcalfe AD, Romer LH, Streuli CH. Integrin-mediated survival signals regulate the apoptotic function of Bax through its conformation and subcellular localization. J Cell Biol. 2000; 149(2): 431-446. [CrossRef]

[23] Yin C, Knudson CM, Korsmeyer SJ, Van Dyke T. Bax suppresses tumorigenesis and stimulates apoptosis in vivo. Nature. 1997; 385(6617): 637-640. [CrossRef]

[24] Ghibelli L, Coppola S, Fanelli C, Rotilio G, Civitareale P, Scovassi A. I., Ciriolo MR. Glutathione depletion causes cytochrome c release even in the absence of cell commitment to apoptosis. FASEB J. 1999; 13: 2031-2036. [CrossRef]

This is an open access article which is publicly available on our journal's website under Institutional Repository at http://dspace.marmara.edu.tr. 